\title{
Model-based analysis of the limits of recycling for its contribution to climate change mitigation
}

\author{
Philipp Schäfer ${ }^{1}$ (D) Mario Schmidt ${ }^{1,2}$ (D) \\ Received: 26 March 2021 / Revised: 29 June 2021 / Accepted: 5 August 2021 / Published online: 5 November 2021 \\ (c) The Author(s) 2021
}

\begin{abstract}
The concept of Circular Economy (CE) and its main strategy recycling are seen as one of the most important measures to achieve sustainable development. Meanwhile, however, concerns are being raised in the scientific community about the conceptualization and orientation of CE. One major issue is that CE is in danger of becoming an end in itself, with the goal of completely closed material cycles. Its contribution to sustainable development is gradually fading into the background. To contribute to this ongoing discussion, we focus in our article on the recycling of metals as part of CE and its contribution to climate protection, as one of the main aspects of sustainable development. Based on life cycle assessment and substance flow modelling carried out in our previous works, we show that metal recycling in most cases requires much less energy and therefore results in much lower greenhouse gas (GHG) emissions than primary production. However, this is by no means without limitations. We show empirically that metal concentration is a significant factor that determines the energy required for recycling. If the metals are too diluted in the technosphere, as it is indeed the case for several metal applications, their recycling require much more energy than the alternative primary production, and thus intensifying rather than mitigating climate change.
\end{abstract}

Keywords Climate change $\cdot$ Cumulative energy demand $\cdot$ End-of-life recycling rates $\cdot$ Metal concentrations $\cdot$ Metal recycling

\section{Modellgestützte Analyse der Grenzen des Beitrags von Recycling zum Klimaschutz}

\section{Introduction}

The Circular Economy (CE) concept and its main strategy recycling have gained momentum. Meanwhile they are considered as one of the most important measures to achieve sustainable development (Ghisellini et al. 2016; Murray et al. 2017) and are anchored in numerous national (Kalmykova et al. 2018; Lieder and Rashid 2016) and supranational strategies, action plans and laws (EC 2014, 2015, 2020). Famous book publications such as Cradle-toCradle (Braungart and McDonough 2002) and, in particular,

Philipp Schäfer

philipp.rouven.schaefer@googlemail.com

1 Institute for Industrial Ecology, Pforzheim University, Tiefenbronner Straße 65, 75175 Pforzheim, Germany

2 Faculty of Sustainability, Leuphana University Lüneburg, Universitätsallee 1, 21335 Lüneburg, Germany the work of the Ellen MacArthur Foundation (EMF 2012, 2013a, 2013b, 2014; Webster 2017) are making a significant contribution to the growing importance of the CE concept in the corporate and social environment and are promoting the vision of completely closed material cycles (Lazarevic and Valve 2017).

Meanwhile, in the literature, many scientists express their concerns about the inconsistencies in the conceptualization of $\mathrm{CE}$ as well as its contribution to sustainable development (Allwood 2014; Blomsma and Brennan 2017; Bocken et al. 2017; Cullen 2017; Kirchherr et al. 2017; Korhonen et al. 2018b). A broad literature review by Geissdoerfer et al. (2017) concludes that three opinions can be found on how CE activities and sustainable development might be related: (1) conditional, (2) beneficial and (3) as a trade-off relation. The first two imply that the more advanced the CE, the more it contributes to sustainable development. The trade-off relation assumes that the contribution of CE to sustainable development has not 
necessarily to be positive, but can also be negative above a certain level. This unclear situation of the CE concept is aptly summarized by Korhonen et al. (2018a): "CE is important for its power to attract both the business community and policy-making community to sustainability work, but it needs scientific research to secure that the actual environmental impacts of CE work toward sustainability." In other words, it must be ensured that CE works as a means to climate change mitigation and sustainable development, and not an end in itself.

The concerns raised by the scientific community are, of course, not unfounded. Over the last decades, products were become more and more complex and the material used to ensure their functionality increased in number. Moreover, the concentrations of the materials used decreased, inter alia due to miniaturization and material efficiency measures. It is known that these developments hinder recycling (Dahmus and Gutowski 2007; Johnson et al. 2007). It is also known, based on physical laws, that the concentration of a material in particular affects the energy requirements of its extraction (Moreau et al. 2017). These energy requirements are directly linked to greenhouse gas (GHG) emissions, and in the case of cumulative energy demands (CEDs), also to several other environmental impacts (Huijbregts et al. 2010). As long as the energy production system is mainly based on fossil fuels, and this is definitely the case for the following decades (IEA 2020), this situation will only slightly change. This issue is intensified by the fact that not only resource extraction requires energy, but energy production also requires resources. Especially for renewable energy technologies the resource consumption is particularly high (Kleijn et al. 2011; The World Bank 2020; IEA 2021).

To make a contribution to this ongoing discussion on $\mathrm{CE}$ we focus in this article on how metal recycling relates to climate change mitigation. Metals are of high relevance in this context as their production contributes with up to $10 \%$ significantly to annual global GHG emissions (IRP 2019), which is due to the high energy demand of this sector with up to 7\% of global (IEA 2019). In future, the society's metal demand will increase, especially if the sustainable development goals (SDGs) will be pursued (Elshkaki et al. 2018). A recent study shows that despite progress in low-carbon metal production, it will be very difficult to achieve the $2^{\circ} \mathrm{C}$ climate target while meeting society's metal needs. CE strategies, especially recycling, are definitely important measures to mitigate this problem (Watari et al. 2020). However, the assumption that increasing endof-life recycling rates (EOL-RRs) to their theoretical maximum will lead to constant GHG emission reduction in overall metal production, like done in Watari et al. (2020), van der Voet et al. (2019) or Ciacci et al. (2016), is quite uncertain in regard to the developments described above. Since it is already an enormous challenge to achieve the $2{ }^{\circ} \mathrm{C}$ target without neglecting societal metal needs, it is important to ensure that too high EOL-RRs do not further thwart climate goals. Because optimizing EOL-RRs for climate change mitigation does not necessarily mean maximizing EOL-RRs.

In this article, we summarize the results of the previous works of the authors (Schäfer 2021; Schäfer and Schmidt 2020) in the three consecutive chapters. First, we show how metals getting diluted during their use phase in the technosphere and how this relates to their EOL-RRs. Second, based on data from life cycle assessment and substance flow models, we present how the energy requirements relate to increasing EOL-RR for copper as an example metal. Using this data for a comparative analysis with the energy requirements for primary production of copper, we determine energetic optimized EOL-RRs for the scope of Germany and the year 2014. Third, we integrate the results from the previous chapters in a more holistic perspective.

\section{Metal concentration and end-of-life recycling rates}

Metals can be produced from two sources: from ores (primary sources), so called primary production or from endof-life products (secondary sources), so called recycling or secondary production. Secondary sources can be very different in their material composition and metal concentrations. This becomes clear after a brief contemplation of all existing products and infrastructures were metals are incorporated. Like secondary sources, primary sources also differ from each other, although the range of their metal concentrations is rather small. An analysis of the concentrations of 48 metals in their primary and secondary sources is depicted in Fig. 1. For the mentioned reasons, the secondary sources are considered differentiated, while the primary sources are indicated by an average concentration for each metal. Each data point therefore displays the concentration of a metal in one of its secondary sources in relation to the average concentration of its primary sources. Additionally, for each metal in each secondary source the current global EOL-RR is included by the shape and color of the data points.

The analysis in Fig. 1 provides three important information. First, it illustrates that the metal concentrations of the secondary sources can vary greatly and are in most cases quite low. Second, in several cases metals are more dilute in secondary sources than in primary sources, in some cases by magnitudes. This is especially true for specialty metals that are needed for advanced technologies. Third, the EOLRR of a metal seems to be determined by the concentration ratio of primary and secondary sources. If a metal is higher concentrated in a secondary source than in its primary source, recycling tends to occur and vice versa. Espe- 
Fig. 1 Comparison of the concentrations of 48 metals in their primary and secondary sources and the related EOL-RRs on a global basis. For each metal, the figure indicates one average concentration in its primary source but different concentrations in several secondary sources. Each data point therefore indicates the concentration of a secondary source in relation to the concentration of the primary source. (Reprinted with permission from (Schäfer and Schmidt 2020). Copyright (2020) American Chemical Society)

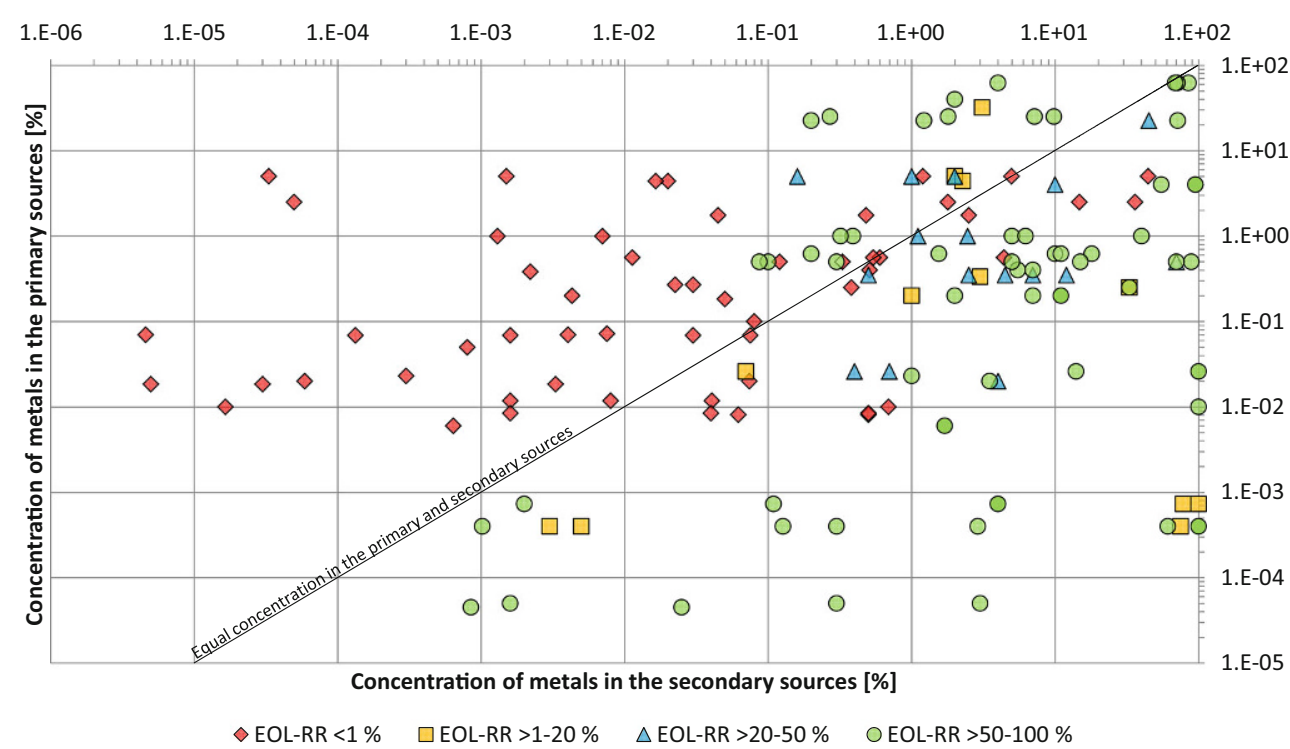

cially for higher concentrations, however, there are several exceptions from this tendency, which we address in Chap. 4.

Since the concentration of a material directly determines the energy required to extract it, as we mentioned in the introduction, this analysis is a first indication that recycling could in some cases require much more energy resulting in higher GHG emissions than alternative primary production.

\section{Optimized end-of-life recycling rates}

In order to shed light on the issue, further sharpened in the previous chapter, of whether recycling above a certain EOL-RR is counterproductive for climate protection, this chapter takes a closer look at the example metal copper. To capture GHG emissions as well as other environmental impacts of primary and secondary copper production, we use the CED as an indicator (Huijbregts et al. 2006). In the following analysis we will answer two questions: (1) how the CED of copper recycling relates to its EOL-RR and (2) is there a point at which the CED of copper recycling exceeds the CED of its primary production?

To determine whether recycling a metal from a specific secondary source is more energetically advantageous compared to primary production, no special method is required. A simple comparison of the two options is sufficient. In contrast, determining an energetically optimal EOL-RR of a metal for a specific scope (time period and region) requires a methodological approach. The basis for this method is provided by the article by Stumm and Davis (1991), its graphical illustration is shown in Fig. 2. The general consideration of this method is that the quantity of a metal in all its available secondary sources can be provided by recycling these sources or else by primary production. The
CED associated with recycling increases disproportionately with an increasing EOL-RR. This is due to the assumption that the high-quality secondary sources are exploited first-i.e. the sources with high metal concentrations. Further EOL-RR increases, the more diluted sources need to be exploited. To achieve an EOL-RR of $100 \%$, all secondary sources have to be fully recycled, even those that contain only very small amounts of the target metal. In proportion to the EOL-RR increase, the CED of primary production is reduced by substitution with metal recycling and therefore linearly decreases. The addition of both functions results in the total CED of metal production, which is valid within the scope of the recycling activities. The minimum of this line indicates the optimal combination of primary and secondary metal production for a specific metal regarding the CED (i.e., the CED-optimized EOL-RR). Recycling beyond this point would lead to a further increase in the overall CED and therefore to negative trade-offs. From the qualitative description of Fig. 2, the CED-optimized EOL-RR is achieved at $\mathrm{x}_{\text {optimized. }}$ In this case, approximately $70 \%$ of the theoretically available metal mass in the secondary sources is recycled; the remaining $30 \%$ is produced from primary sources. The total CED to recycle $70 \%$ occurs at $\mathrm{y}_{\mathrm{s}}$, and the total CED of the remaining $30 \%$ of primary production is at $y_{p}$. The resulting $y_{\text {total }}=y_{s}+y_{p}$ is thus the average CED of the total mass of metal production (equivalent to an EOLRR of $100 \%$ ).

Of course, due to the several different secondary sources of a specific metal, the description of the CED-EOL-RR relation by a function can only be an approximation in the best case. Therefore, for the following analysis we use discrete data points. The further assumptions underlying the method as well as further concrete mathematical descrip- 
Fig. 2 Qualitative description of the method for calculating the CED-optimized EOL-RR (Schäfer and Schmidt (2020) modified from Stumm and Davis (1991)). (Reprinted with permission from (Schäfer and Schmidt 2020). Copyright (2020) American Chemical Society)
Fig. 3 Application of the method for calculating the CEDoptimized EOL-RR in Fig. 2 to copper production under current collection rates. The EOL-RR is scaled to $100 \%$ equaling $1 \mathrm{~kg}$ of copper. Valid for Germany and the year 2014. (Schäfer 2021, translated from German)
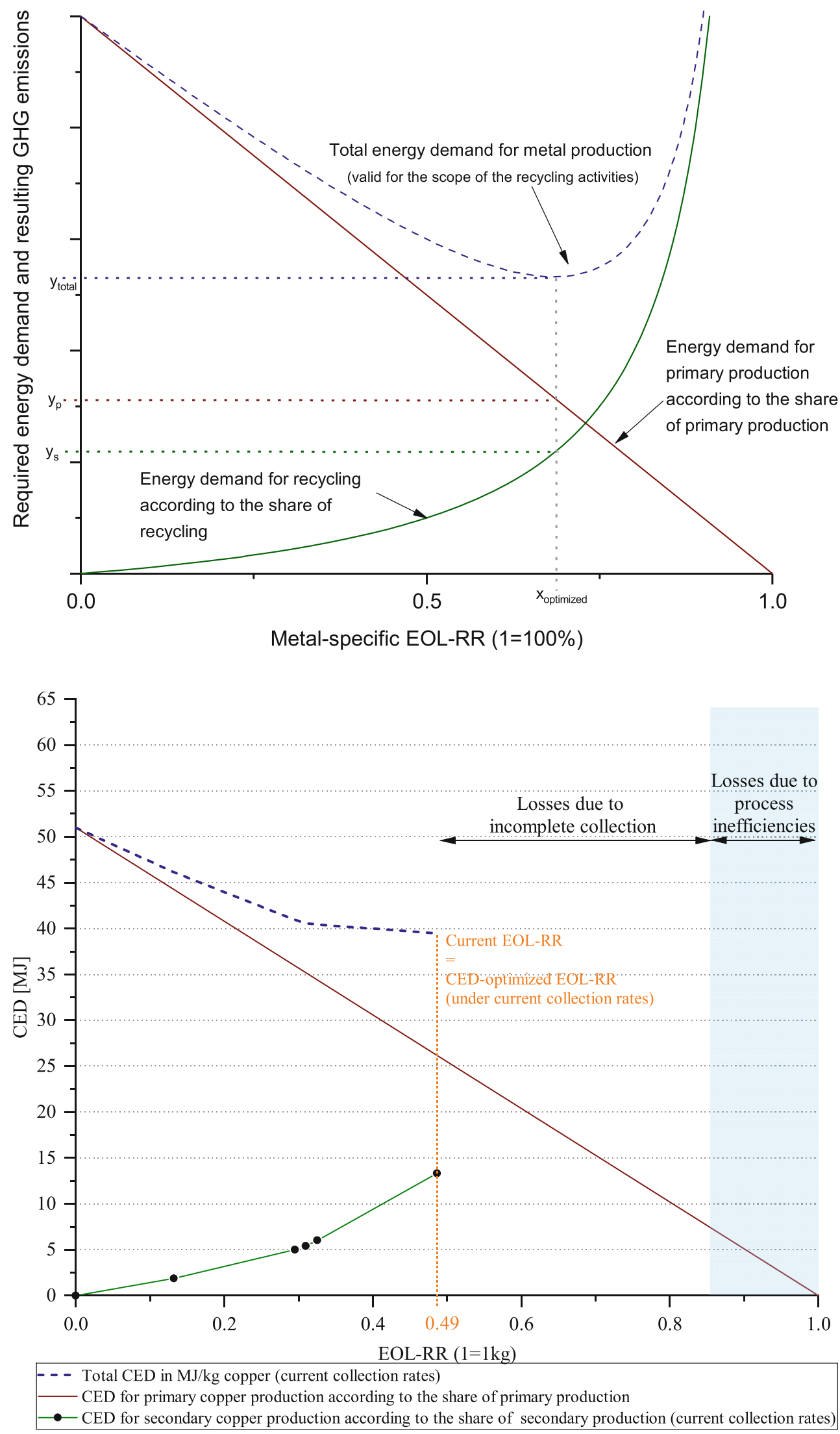
Fig. 4 Application of the method for calculating the CEDoptimized EOL-RR in Fig. 2 to copper production under complete collection rates (scenario based). The EOL-RR is scaled to $100 \%$ equaling $1 \mathrm{~kg}$ of copper. Valid for Germany and the year 2014. (Schäfer 2021, translated from German)

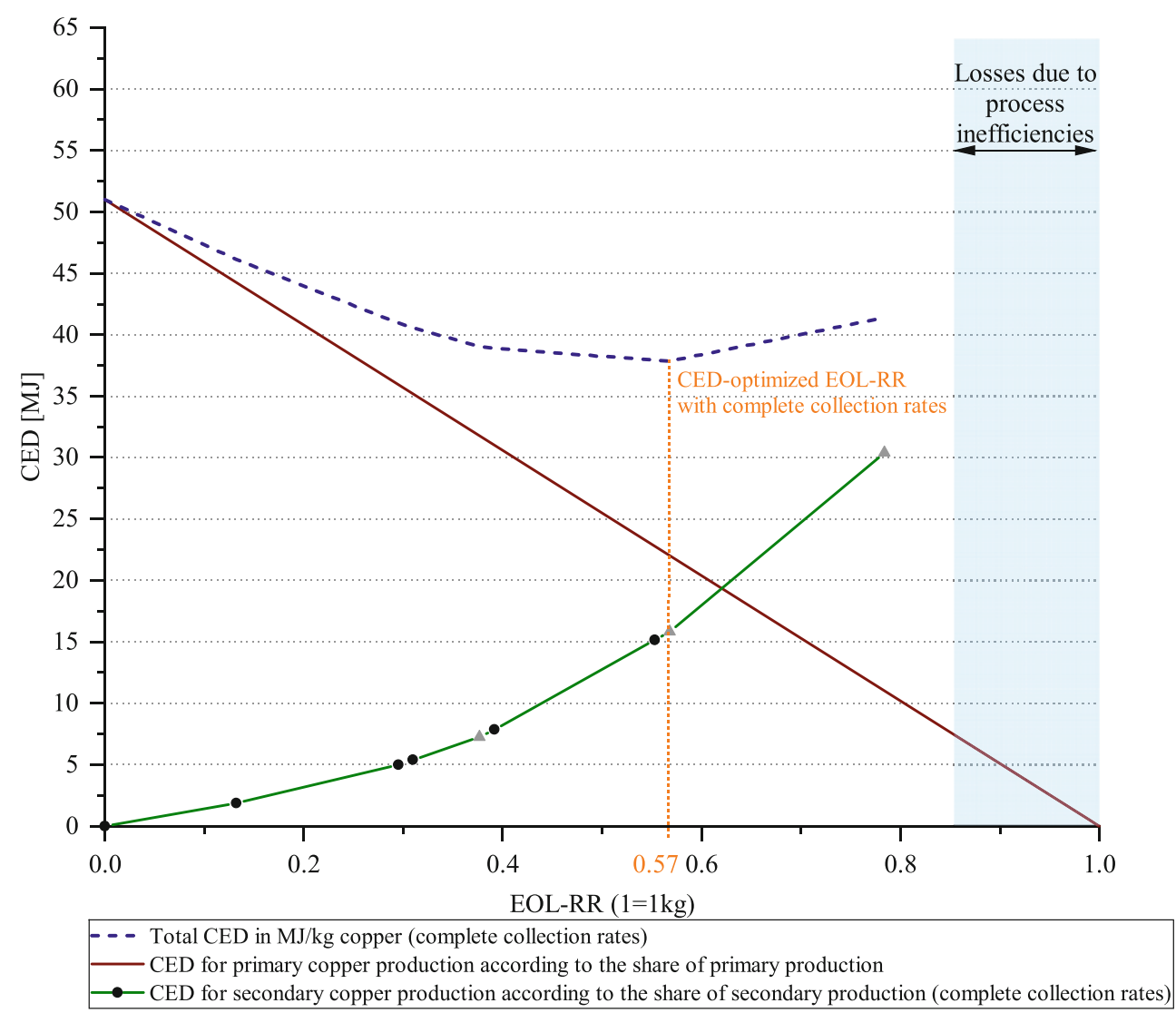

tions can be found in the previous publications (Schäfer 2021; Schäfer and Schmidt 2020).

For applying this method to specific metals, extensive data is needed, generated in the previous works by life cycle assessment and substance flow models for three metals, copper, tantalum and cobalt. The results for copper for the scope of Germany and the year 2014 are displayed in Fig. 3. This analysis shows, that copper is currently recycled from all its secondary sources (every data point represents one secondary source), resulting in overall CED savings. Thus, the current EOL-RR of copper in Germany is the same as its CED-optimized EOL-RR, under the current collection rates and process efficiencies. The latter ones determine the losses during the mechanical and metallurgical recycling process steps. Nevertheless, the curve describing the total CED of copper production is almost horizontal in the range of the current EOL-RR, indicating that the CEDs for recycling the last secondary sources in the order is close to the CED of primary production. If further increases in e.g. process efficiencies lead to higher CEDs for recycling, recycling of the last sources may be more energy intensive than primary production. For increases in collection rates, we simulated different scenarios of how the increase in collection rate relates to the CED of collection. One scenario is shown in Fig. 4, which assumes that the CED for collection increases with the increase in collec- tion rate. Under this scenario, the CED-optimized EOL-RR only slightly changes from $49 \%$ to $57 \%$ with complete collection rates. The amount of secondary sources which are additionally collected in this fictive scenario are displayed as separate data points (grey triangles). One of these data points is outside the CED-optimized EOL-RR. Due to its increased CED for complete collection, the recycling of this secondary source needs a higher total CED than the alternative primary production and would therefore lead to negative impacts on climate protection.

Of course, these analyses are based on models and are therefore only close to reality. Nevertheless, the results clearly indicate on an empirical basis that recycling is limited in its contribution to mitigate climate change; moreover, it can thwart it. Furthermore, copper as a bulk metal is relatively highly concentrated in its secondary sources and is therefore located on the right-hand side of Fig. 1 below or close to the diagonal line. Anyway, its recycling is already close to its limits. This seems to be a strong indication that recycling metals from secondary sources, which are located on the left-hand side of Fig. 1 and above the diagonal line, will probably increase climate change. However, there are several aspects that need to be considered. These are further discussed in the following chapter. 
Fig. 5 Comparison of the CEDconcentration-correlations of primary (blue triangles) and secondary metal production (green points) (Schäfer 2021, translated from German)

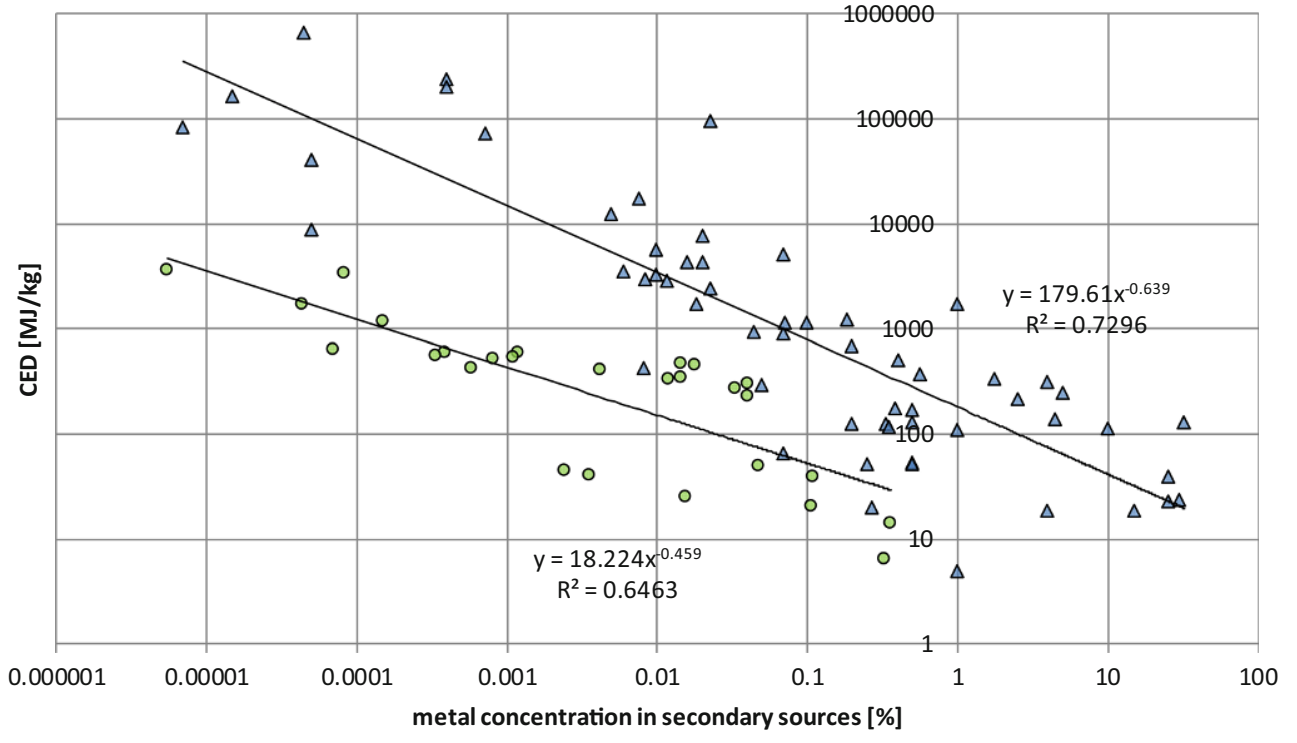

\section{Integration in a holistic perspective}

Besides copper, we have also modelled the recycling of tantalum and cobalt in our previous works and calculated the CEDs for recycling for each of their secondary sources. In the following Fig. 5 we have displayed all these calculated CEDs for recycling (copper, cobalt, tantalum) in relation to the concentration of the metal being recycled from its secondary source (green points). These values are compared to the CEDs and concentrations of the primary production of several metals (blue triangles). There are two main findings in this comparative analysis. First, the CEDs for metal production are dependent on the metal concentrations. This is true for both, the primary and secondary metal production. Second, the tendency can be seen that recycling requires less CED than primary production at the same metal concentration. This mainly is due to two effects occurring during recycling: dismantling and allocation effects. Dismantling effects are best explained by an example: tantalum is quite low concentrated in electronic products, but located on a specific component-the printed wiring board. With relatively small effort, this component can be dismantled and thus the tantalum concentration can be significantly increased. In case of primary production such effort efficient concentration increases are not possible. The ore has to be mined, crushed and further processed as a whole. Unlike the dismantling effect, the allocation effect also occurs in primary production. Secondary sources as well as primary sources usually consist of several different metals and materials. These metals and materials, are, if technically and economically feasible, produced together from their sources in so-called multi-output processes. To calculate separate CEDs for each of these metals, an allocation method is needed, as in most cases the metal produc- tion processes support the production of all metals at the same time, such as collection or mining and shredding or crushing. In our models, we followed the recommendation of ISO 14040/44 (DIN 2009, 2018) and the argumentation by Bigum et al. (2012) and used economic allocation for all processes that provide economic benefits. For all other processes, especially collection processes, which are in fact disposal measures of end-of-life products from an end-consumer perspective, we applied mass allocation. Secondary sources usually contain many more valuable materials, in number and mass, than ores do (in general, the largest proportion in ores is gangue), and thus more materials are usually produced or recycled within the same process chain. Therefore, allocation effects usually have a stronger impact in recycling processes than in primary production.

Of course, the findings of this comparative analysis are limited to a certain extent, as we only have data for the recycling of three metals. To minimize these uncertainties, the three metals analyzed were chosen as typical example metals (copper for bulk metals, tantalum and cobalt for specialty metals). Thus, despite a limited number of metals, a representative overview can be given. Nevertheless, there will be numerous individual cases that deviate from the identified tendencies. One example is indium in LCD screens. Its concentration in this secondary source is about 10-100 ppm (Ciacci et al. 2018). The indium concentration in the ores varies between 20 and $350 \mathrm{ppm}$ and is therefore only slightly higher (Frenzel et al. 2017; Werner et al. 2018). However, according to the current technology, indium recycling from screens, which would be carried out by dismantling, inter alia, would require considerably more CED than primary indium production (Amato et al. 2017; ecoinvent 2016). 
Fig. 6 Influence of the concentration ratio and the theoretically available monetary value (annual global metal mass multiplied with its market price) on the secondary source-specific EOL-RR of 48 metals. Modified version of Fig. 1. (Schäfer 2021, translated from German)

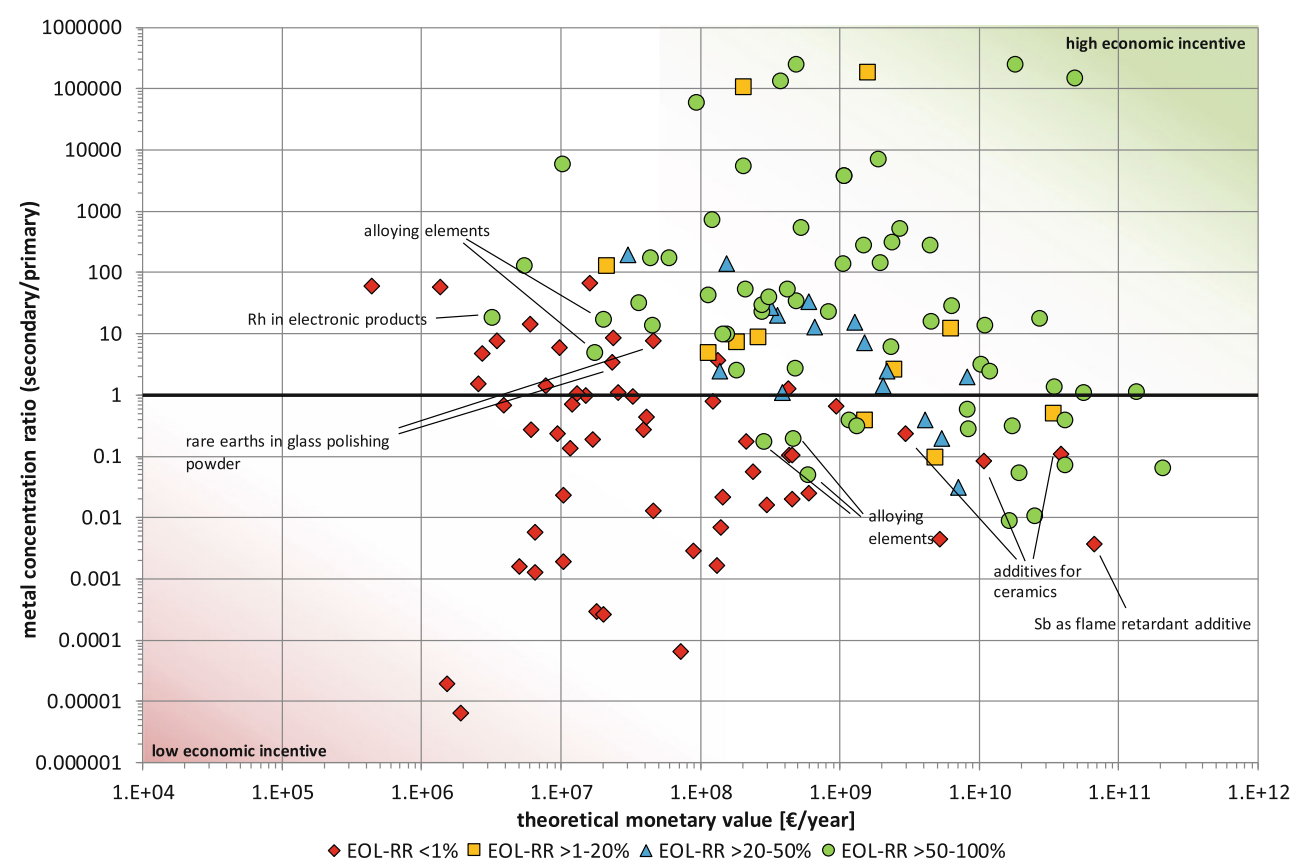

$\diamond$ EOL-RR $<1 \% \square$ EOL-RR $>1-20 \% \triangle$ EOL-RR $>20-50 \%$ O EOL-RR $>50-100 \%$
Since recycling is done by private companies, it can generally be assumed that recycling is only practiced when it is economical. In the past, the studies by Johnson et al. (2007) and Dahmus and Gutowski (2007) have already pointed out on the basis of exemplary studies that cost-intensive recycling only takes place for metals with correspondingly high market prices. The revenue that is achieved through these market prices must therefore be greater than the costs for recycling.

Fig. 1 in Chap. 2 shows that a metal from a secondary source tends to be recycled if its concentration is higher than that of the alternative primary source. This phenomenon is due to the fact that the concentration is directly related to the (energetic) effort required for metal recycling, which in turn is related to the costs. However, this illustration also shows that there are several exceptions, as we mentioned already in the previous chapter. Of course, one reason is that the concentration ratio can only be an approximate indicator for the energy requirements and therefore for the variable cost. In order to be able to operate economically, however, the degression of fixed costs (investment costs, etc.) is also crucial, which can only be achieved through correspondingly high revenues. The amount of metal available for recycling from a secondary source must therefore be sufficiently high, as well as the market price of the metal.

Fig. 6 is a modified version of Fig. 1. In this analysis we included the theoretically available monetary value of the several metals in its several secondary sources on the $\mathrm{x}$-axis. The concentration ratio is plotted on the $\mathrm{y}$-axis. If the ratio equals 1 , the metal has the same concentration in its primary and secondary source. For values below 1, the metal is less concentrated in its secondary source than in its primary source; for values above 1 , vice versa.

Fig. 6 shows that recycling tends not to take place when the available monetary values are low, even if the metal concentrations in the secondary sources are higher than in the primary sources. Exceptions here are precious metals, such as rhenium in electronic waste. These metals are produced as co-products via the copper production route (Langner 2011) and can be understood as side effects of the copper metallurgy that would also take place in the absence of precious metals. Thus, their concentrations and their available monetary values are not decisive for their EOL-RRs. A similar case exists with alloying elements, such as niobium in steel alloys. Here, no recycling of the individual alloying element takes place, but of the alloy as a whole. Above an annual monetary value of more than one billion euros, metal recycling from secondary sources also increasingly takes place at high EOL-RRs when its concentrations are lower compared to those of primary sources. The fact that their recycling can nevertheless compete with primary production is explained by the effects identified in this chapter, which, despite lower concentrations, enable recycling to be more effort- and thus also more cost-efficient than primary production. In addition, we are dealing here almost exclusively with bulk metals whose concentration ratios are below 1, but their concentrations in the secondary sources are nevertheless relatively high (usually significantly above $1 \%$ ). Thereby, recycling is generally favored. Metals in this range of high annual monetary values that are not recycled despite of moderate concentration ratios are e.g. used as additives in ceramics. Recycling of these metals is not possible for technical reasons. Another example for missing 
Fig. 7 Remaining theoretical GHG emission saving potentials (modified version of Fig. 6, size of bubbles indicates theoretical saving potential, GHG emissions for recycling are not included) (Schäfer 2021, translated from German)

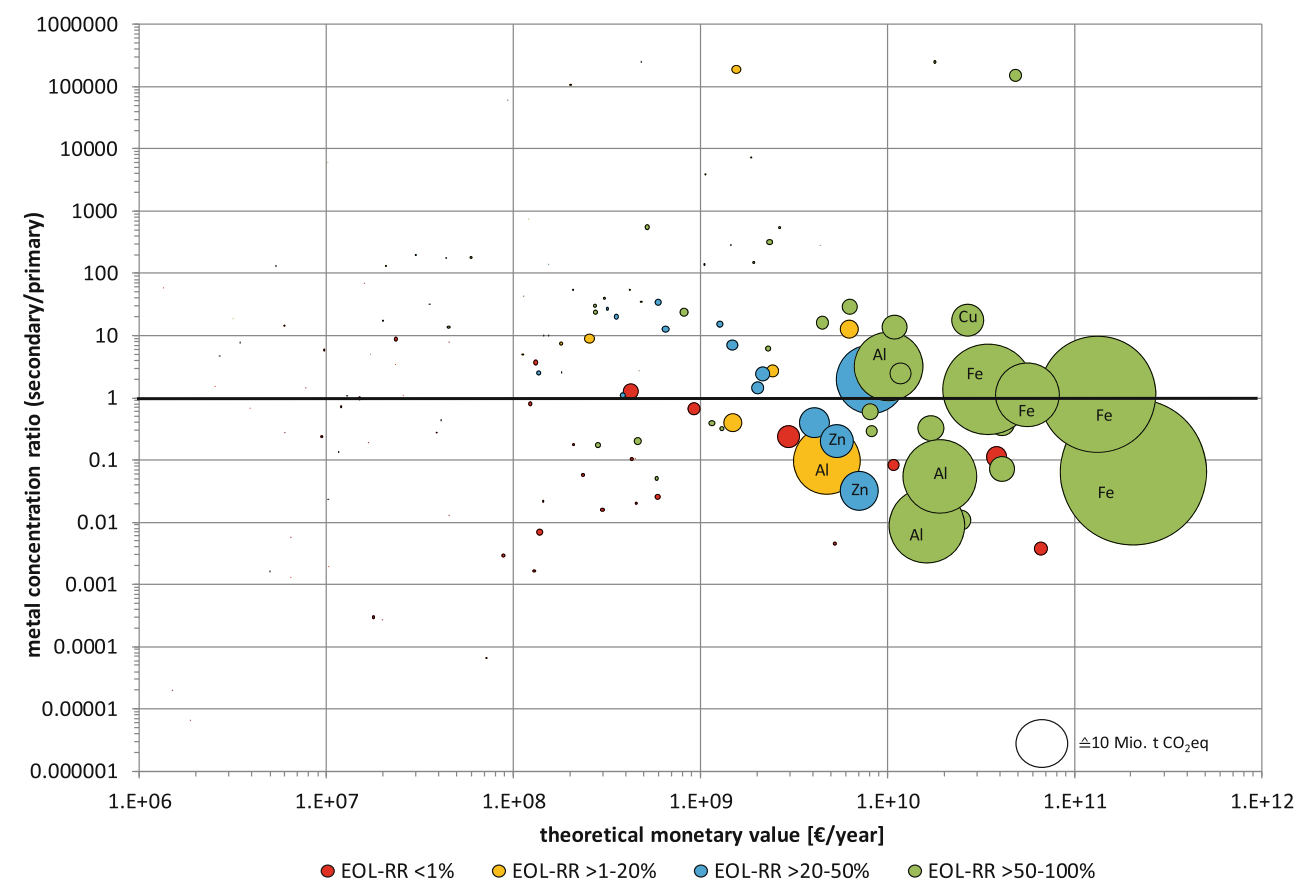

recycling technologies is antimony which is used as a flame retardant (Ciacci et al. 2015). However, the antimony concentration in such applications is decisively lower than in primary sources.

Fig. 6 provides valuable information on the framework conditions of recycling and is therefore an empirical explanation of the famous periodic table picture of metal EOLRRs published by UNEP (2011). The higher the concentration ratio (secondary > primary) and the higher the monetary value, the higher the economic incentive to recycle and the higher the EOL-RRs. Furthermore, Fig. 6 in combination with Fig. 5 provides insightful information on what needs to be done to realize further GHG emission savings through recycling. It is shown in Fig. 5 that at concentration ratio of higher 1 and also just below 1, recycling tends to be more energy efficient than primary production. Fig. 6 shows, however, that these potential savings will only be realized if correspondingly high monetary values are available. In order to also use the remaining GHG emission savings, i.e. the secondary sources whose concentration ratios are higher 1 , but whose available monetary values are rather low, political interventions may be necessary. It is a matter of influencing the economically acting recycling system, whose current EOL-RR basically represent economic optima, in such a way that energetic and thus ecological optima are achieved. Examples of remaining GHG emission saving potentials are rare earth metals used in glass polishing powders or as glass additives. Recycling processes for these secondary sources already exist (Binnemans et al. 2013). Their dissipation rates in the use phase are also negligible (Ciacci et al. 2015). The available monetary values seem to be the only obstacle to their recycling. Possible political interventions should aim, inter alia, at a better interconnection of the national and transnational recycling system in order to realize material flow bundling for the relevant secondary sources to achieve monetary values in a sufficient order of magnitude for an economic centralized recycling.

The question remains where the greatest remaining saving potentials are located. The answer is depicted in Fig. 7, a further modified version of Fig. 6 . The size of the bubbles indicates the remaining theoretical GHG savings potential of the respective metal in the respective secondary source. These GHG saving potentials were calculated by multiplying the remaining available mass for recycling by the inherent GHG emissions of the metal (GHG emissions of primary production). It is obvious that the bulk metals, especially iron and aluminum, have the greatest remaining savings potential, even though they are already recycled at high percentages. From a perspective of an effective climate protection measure, the recycling of specialty metals is rather subordinate. Their recycling is more relevant for increasing the resilience for possible supply risks, as specialty metals are often rated as critical (Graedel et al. 2015).

\section{Discussion, outlook and conclusion}

There is one big issue, we have not addressed yet- the narrative of resource depletion. It is a decades-old and still ongoing discussion about peak production, declining ore grades and calculated lifetimes as indicators for scarcity 
(Tilton 1996; Schmidt 2019). Of course, the amount of resources on earth is limited. If we would run out of important resources in the near future, there would be good reasons to practice recycling to the maximum extent at all costs. Otherwise we would not be able to maintain our economy and society. In the past, the depletion of certain resources has often been predicted (e.g. Meadows et al. 1972). Today we know that these predictions did not come true. So is there any truth about the impending resource depletion? To give a short answer to this complex topic, we would like to quote Meinert et al. (2016): "We do not know what the limits to mineral resources might be, but we do know that we have not come close to reaching them yet." The biggest misunderstanding, and thus the reason for wrong predictions, is that we still know too less about the resource deposits that can be mined under current and future conditions. A recent study by Jowitt et al. (2020) has empirically proven that there is no evidence of resource depletion and therefore refute statements by other researchers that a range of metals will become scarce within the next 50 years (Kerr 2014; Sverdrup et al. 2014, 2019).

In addition to the focused energy requirements and GHG emissions, there are of course several local social and environmental aspects which are also important to consider. This is especially true for metals that are mined in regions of the world with unstable political conditions or weak environmental governance. Think, for example, of cobalt mining in the Congo or gold mining in Burkina-Faso. Such poor local conditions are complex issues determined by numerous historical, cultural, political and socio-economic factors. Improving these conditions are typically social, cultural and political tasks and thus not physical phenomena like e.g. the energy consumption and ore grade relation that determines GHG emissions. Nevertheless, they are highly relevant and should be assessed and evaluated in further research to complement our results.

The analysis presented is primarily a spotlight on the current situation, with the current technology. Further developments in recycling technologies need to be analyzed, as it can be assumed that technologies will become more efficient and thus, in future, it will probably be possible to recycle more material from a secondary source with less energy input. Such developments may compensate for further increases in product complexity and decreasing metal concentrations.

Coming back to our initial research question on how metal recycling relates to climate change mitigation. The recycling of metals can and currently does contribute to climate change mitigation, there is no doubt about that. However, we have shown that this contribution is limited. Depending on their applications, metals can be highly diluted in the technosphere. In many cases, this is due to the intended strategy of dematerialization to save resources and the associated environmental impacts. However, if metals are much lower concentrated in the technosphere than in the ecosphere, i.e. their natural primary sources, this is a strong indication that their recycling requires more energy and thus leads to more GHG emissions than primary production. In general, the energy requirements of metal recycling are highly dependent on the quality, especially the metal concentration, of the secondary sources. Consequently, as secondary sources further decrease in quality and dematerialization progresses, more and more tradeoffs with recycling and its climate protection potential will occur. These findings, underpinned by empirical data, are crucial for the ongoing scientific discussion on the conceptualization and orientation of recycling and CE.

Funding Open Access funding enabled and organized by Projekt DEAL.

Conflict of interest P. Schäfer and M. Schmidt declare that they have no competing interests.

Open Access This article is licensed under a Creative Commons Attribution 4.0 International License, which permits use, sharing, adaptation, distribution and reproduction in any medium or format, as long as you give appropriate credit to the original author(s) and the source, provide a link to the Creative Commons licence, and indicate if changes were made. The images or other third party material in this article are included in the article's Creative Commons licence, unless indicated otherwise in a credit line to the material. If material is not included in the article's Creative Commons licence and your intended use is not permitted by statutory regulation or exceeds the permitted use, you will need to obtain permission directly from the copyright holder. To view a copy of this licence, visit http://creativecommons.org/licenses/by/4. $0 /$.

\section{References}

Allwood JM (2014) Squaring the circular economy: the role of recycling within a hierarchy of material management strategies. In: Worrell E, Reuter MA (eds) Handbook of recycling. State-of-theart for practitioners, analysts, and scientists. Elsevier, Amsterdam, pp 445-479

Amato A, Rocchetti L, Beolchini F (2017) Environmental impact assessment of different end-of-life LCD management strategies. Waste Manag 59:432-441. https://doi.org/10.1016/j.wasman. 2016.09.024

Bigum M, Brogaard L, Christensen TH (2012) Metal recovery from high-grade WEEE: a life cycle assessment. J Hazard Mater 207-208:8-14. https://doi.org/10.1016/j.jhazmat.2011.10.001

Binnemans K, Jones PT, Tom P, Blanpain B, van Gerven T, Yongxiang Y, Walton A, Buchert M (2013) Recycling of rare earths. A critical review. J Clean Prod 51:1-22. https://doi.org/10.1016/j. jclepro.2012.12.037

Blomsma F, Brennan G (2017) The emergence of circular economy: a new framing around prolonging resource productivity. J Ind Ecol 21(3):603-614. https://doi.org/10.1111/jiec.12603

Bocken NMP, Olivetti EA, Cullen JM, Potting J, Lifset R (2017) Taking the circularity to the next level: a special issue on the circular economy. J Ind Ecol 21(3):476-482. https://doi.org/10.1111/jiec. 12606

Braungart M, McDonough W (2002) Cradle to Cradle. Einfach intelligent produzieren. Piper, München 
Ciacci L, Harper EM, Nassar NT, Reck BK, Graedel TE (2016) Metal dissipation and inefficient recycling intensify climate forcing. Environ Sci Technol. https://doi.org/10.1021/acs.est.6b02714

Ciacci L, Reck BK, Nassar NT, Graedel TE (2015) Lost by design. Environ Sci Technol 49(16):9443-9451. https://doi.org/10.1021/ es505515z

Ciacci L, Werner TT, Vassura I, Passarini F (2018) Backlighting the European indium recycling potentials. J Ind Ecol 16(6):687. https://doi.org/10.1111/jiec. 12744

Cullen JM (2017) Circular economy: theoretical benchmark or perpetual motion machine? J Ind Ecol 21(3):483-486. https://doi.org/ 10.1111/jiec. 12599

Dahmus JB, Gutowski TG (2007) What gets recycled? An information theory based model for product recycling. Environ Sci Technol 41(21):7543-7550. https://doi.org/10.1021/es062254b

Deutsches Institut für Normung (DIN) (2009): DIN EN ISO 14040. Umweltmanagement - Ökobilanz - Grundsätze und Rahmenbedingungen (ISO 14040:2006): Beuth Verlag.

Deutsches Institut für Normung (DIN) (2018): DIN EN ISO 14044. Umweltmanagement - Ökobilanz - Anforderungen und Anleitungen (ISO 14044:2006): Beuth Verlag.

ecoinvent (2016) market for indium, GLO. Datenbankversion 3.6. https://www.ecoinvent.org/. Accessed: 01 May 2020

Ellen MacArthur Foundation (EMF) (2012) Towards The Circular Economy. Economic and business rationale for an accelerated transition

Ellen MacArthur Foundation (EMF) (2013a) Towards Circular Economy vol 1. Economic and business rationale for an accelerated transition

Ellen MacArthur Foundation (EMF) (2013b) Towards Circular Economy vol 2. Opportunities for the consumer goods sector

Ellen MacArthur Foundation (EMF) (2014) Towards circular economy vol 3. Accelerating scale-up across global supply chains

Elshkaki A, Graedel TE, Ciacci L, Reck BK (2018) Resource demand scenarios for the major metals. Environ Sci Technol 52(5):2491-2497. https://doi.org/10.1021/acs.est.7b05154

European Commission (EC) (2014) Towards a circular economy: A zero-waste programme for Europe (Communication from the Comission to the European Parliament, the council, the Eurpoean Economic and Social Comittee and the Comittee of the Regions. Brüssel)

European Commission (EC) (2015) Closing the loop - An EU action plan for the Circular Economy (Communication from the Comission to the European Parliament, the council, the Eurpoean Economic and Social Comittee and the Comittee of the Regions. Brüssel)

European Commission (EC) (2020) A new Circular Economy Action Plan For a cleaner and more competitive Europe (Communication from the Comission to the European Parliament, the council, the Eurpoean Economic and Social Comittee and the Comittee of the Regions)

Frenzel M, Mikolajczak C, Reuter MA, Gutzmer J (2017) Quantifying the relative availability of high-tech by-product metals - the cases of gallium, germanium and indium. Resour Policy 52:327-335. https://doi.org/10.1016/j.resourpol.2017.04.008

Geissdoerfer M, Savaget P, Bocken NMP, Hultink EJ (2017) The circular economy - a new sustainability paradigm? J Clean Prod 143:757-768. https://doi.org/10.1016/j.jclepro.2016.12.048

Ghisellini P, Cialani C, Ulgiati S (2016) A review on circular economy: the expected transition to a balanced interplay of environmental and economic systems. J Clean Prod 114:11-32. https://doi.org/ 10.1016/j.jclepro.2015.09.007

Graedel TE, Harper EM, Nassar NT, Nuss P, Reck BK (2015) Criticality of metals and metalloids. Proc Natl Acad Sci USA 112(14):4257-4262. https://doi.org/10.1073/pnas.1500415112

Huijbregts MAJ, Rombouts LJA, Hellweg S, Frischknecht R, Hendriks AJ, van de Meent D et al (2006) Is cumulative fossil energy demand a useful indicator for the environmental performance of products? Environ Sci Technol 40(3):641-648. https://doi.org/10. $1021 / \mathrm{es} 051689 \mathrm{~g}$

Huijbregts MAJ, Hellweg S, Frischknecht R, Hendriks HWM, Hungerbühler K, Hendriks AJ (2010) Cumulative energy demand as predictor for the environmental burden of commodity production. Environ Sci Technol 44(6):2189-2196. https://doi.org/10.1021/ es902870s

International Energy Agency (IEA) (2019) World energy statistics 2019. International Energy Agency (IEA) (World energy statistics), Paris

International Energy Agency (IEA) (2020) World energy outlook 2020. IEA Publications, Paris

International Energy Agency (IEA) (2021) The role of critical world energy outlook special report minerals in clean energy transitions

International Resource Panel (IRP) (2019) Global resources outlook 2019: natural resources for the future we want. A report of the international resource panel. United nations environment programme

Johnson J, Harper EM, Lifset R, Graedel TE (2007) Dining at the periodic table. Metals concentrations as they relate to recycling. Environ Sci Technol 41(5):1759-1765. https://doi.org/10.1021/ es060736h

Jowitt SM, Mudd GM, Thompson JFH (2020) Future availability of non-renewable metal resources and the influence of environmental, social, and governance conflicts on metal production. Commun Earth Environ. https://doi.org/10.1038/s43247-020-0011-0

Kalmykova Y, Sadagopan M, Rosado L (2018) Circular economy from review of theories and practices to development of implementation tools. Resour Conserv Recycl 135:190-201. https://doi. org/10.1016/j.resconrec.2017.10.034

Kerr RA (2014) The coming copper peak. science 343(6172):722-724. https://doi.org/10.1126/science.343.6172.722

Kirchherr J, Reike D, Hekkert M (2017) Conceptualizing the circular economy: an analysis of 114 definitions. Resour Conserv Recycl 127:221-232. https://doi.org/10.1016/j.resconrec.2017.09.005

Kleijn R, van der Voet E, Kramer GJ, van Oers L, van der Giesen C (2011) Metal requirements of low-carbon power generation. Energy 36(9):5640-5648. https://doi.org/10.1016/j.energy.2011.07. 003

Korhonen J, Honkasalo A, Seppälä J (2018a) Circular economy: the concept and its limitations. Ecol Econ 143:37-46. https://doi.org/ 10.1016/j.ecolecon.2017.06.041

Korhonen J, Nuur C, Feldmann A, Birkie SE (2018b) Circular economy as an essentially contested concept. J Clean Prod 175:544-552. https://doi.org/10.1016/j.jclepro.2017.12.111

Langner BE (2011) Understanding copper. Technologies, markets, business, 1st edn. B. E. Langner, Winsen

Lazarevic D, Valve H (2017) Narrating expectations for the circular economy: towards a common and contested European transition. Energy Res Soc Sci 31:60-69. https://doi.org/10.1016/j.erss. 2017.05.006

Lieder M, Rashid A (2016) Towards circular economy implementation: a comprehensive review in context of manufacturing industry. J Clean Prod 115:36-51. https://doi.org/10.1016/j.jclepro. 2015.12.042

Meadows DH, Meadows DL, Randers J, Behrens WW (1972) The limits to growth. A report for the club of rome's project on the predicament of mankind. Universe Books,

Meinert L, Robinson G, Nassar N (2016) Mineral resources: reserves, peak production and the future. Resources 5(1):14. https://doi.org/ 10.3390/resources5010014

Moreau V, Sahakian M, van Griethuysen P, Vuille F (2017) Coming full circle: why social and institutional dimensions matter for the circular economy. J Ind Ecol 21(3):497-506. https://doi.org/10. $1111 /$ jiec. 12598

Murray A, Skene K, Haynes K (2017) The circular economy: an interdisciplinary exploration of the concept and application in a global 
context. J Bus Ethics 140(3):369-380. https://doi.org/10.1007/ s10551-015-2693-2

Schäfer P (2021) Recycling - ein Mittel zu welchem Zweck? Modellbasierte Ermittlung der energetischen Aufwände des Metallrecyclings für einen empirischen Vergleich mit der Primärgewinnung. Dissertation. Springer Spektrum, Berlin Heidelberg

Schäfer P, Schmidt M (2020) Discrete-point analysis of the energy demand of primary versus secondary metal production. Environ Sci Technol 54(1):507-516. https://doi.org/10.1021/acs.est.9b05101

Schmidt M (2019) Scarcity and environmental impact of mineral resources-an old and never-ending discussion. Resources 8(1):2. https://doi.org/10.3390/resources 8010002

Stumm W, Davis J (1991) Kann Recycling die Umweltsbeeinträchtigung vermindern? Die Kreisläufe können nicht geschlossen werden. In: Seidel E, Strebel H (eds) Umwelt und Ökonomie. Reader zur ökologieorientierten Betriebswirtschaftslehre, 1st edn. Gabler, Wiesbaden, pp 75-87

Sverdrup HU, Olafsdottir AH, Ragnarsdottir KV (2019) On the longterm sustainability of copper, zinc and lead supply, using a system dynamics model. Resour Conserv Recycl 4:100007. https://doi. org/10.1016/j.rcrx.2019.100007

Sverdrup HU, Ragnarsdottir KV, Koca D (2014) On modelling the global copper mining rates, market supply, copper price and the end of copper reserves. Resour Conserv Recycl 87:158-174. https://doi.org/10.1016/j.resconrec.2014.03.007

Tilton JE (1996) Exhaustible resources and sustainable development. Two different paradigms. Resour Policy 22(1/2):91-97

United Nations Environment Programme (UNEP) (2011) Recycling rates of metals - a status report (Unter Mitarbeit von T. E. Graedel, Julian Allwood, Jean-Pierre Birat, Barbara K. Reck, Scott F. Sibley, Guido Sonnemann et al.)

van der Voet E, van Oers L, Verboon M, Kuipers K (2019) Environmental implications of future demand scenarios for metals: methodology and application to the case of seven major metals. J Ind Ecol 23(1):141-155. https://doi.org/10.1111/jiec.12722

Watari T, Nansai K, Giurco D, Nakajima K, McLellan B, Helbig C (2020) Global metal use targets in line with climate goals. Environ Sci Technol 54(19):12476-12483. https://doi.org/10.1021/acs.est. $0 \mathrm{c} 02471$

Webster K (2017) The circular economy. A wealth of flows, 2nd edn. Ellen MacArthur Foundation Publishing, Cowes, Isle of Wight

Werner TT, Ciacci L, Mudd GM, Reck BK, Northey SA (2018) Looking down under for a circular economy of indium. Environ Sci Technol 52(4):2055-2062. https://doi.org/10.1021/acs.est. $7 \mathrm{~b} 05022$

World Bank (2020) Minerals for climate action: the mineral intensity of the clean energy transition 